\title{
Research on Human Resource Management of Equipment Manufacturing Industry under the Background of Replacement of Old Drivers for New Ones
}

\author{
Liezhi Shen, Yigang Wang \\ School of Business Administration, University of Science and Technology Liaoning, Anshan, 114051, \\ Liaoning, China
}

\begin{abstract}
:
According to the basic theory and requirements of the replacement of old drivers for new ones, it points out the new requirements of the equipment manufacturing industry in the process of traditional drivers upgrading and new drivers cultivation. Based on the existing problems of human resources management in the equipment manufacturing industry in terms of knowledge level, professional quality and age structure, supporting strategies are provided to promote the replacement of old drivers for new ones from three aspects: the introduction of high-level talents, the improvement of the quality of all staff and the cultivation of innovative ability.
\end{abstract}

Keywords: Equipment manufacturing industry, The replacement of old drivers for new ones, High-level talents

\section{INTRODUCTION}

From the perspective of global economic development, it is the general trend of social development to speed up the replacement of old drivers for new ones, that is, to cultivate new drivers and enhance the traditional ones. As the equipment manufacturing industry, which is the main component of the real economy, plays a fundamental, strategic and pillar role in promoting the development of the national economy, it is currently a very important task to realize the upgrading and transformation of China's equipment manufacturing industry and the cultivation of new drivers in the face of the new situation, new tasks and new requirements of the replacement of old drivers for new ones. 
Since the equipment manufacturing industry is the main field of employment in China, which can accommodate $90 \%$ of the employed population, the number, structure and ability of scientific and technical personnel have become the most critical factors restricting the promotion of old drivers and the cultivation of new ones in China's manufacturing industry. How to strengthen the human resource management of the equipment manufacturing industry in accordance with the requirements of the replacement of old drivers for new ones has become an urgent problem to be solved in the development of China's equipment manufacturing industry [1].

\section{NEW REQUIREMENTS FOR HUMAN RESOURCE MANAGEMENT OF EQUIPMENT MANUFACTURING UNDER THE REPLACEMENT OF OLD DRIVERS FOR NEW ONES}

The personnel needed in the equipment manufacturing industry generally include technical R\&D personnel, production personnel, marketing specialists and managers, among which the production personnel should include project engineers, technicians, skilled workers and non-skilled workers, so that the main body of personnel training in the equipment manufacturing industry is to cultivate technical talents among the production personnel in the manufacturing industry, who can rely on their own professional knowledge to create operational skills or effective behavior patterns by summarizing various practical work and directly apply them to related production activities. According to the demand for personnel setup in the equipment manufacturing industry and the need for the replacement of old drivers for new ones, new requirements are put forward for human resources.

\subsection{Demand for Professional and Technical Personnel with Innovative Ability}

Since the professional and technical talents are the soul force of the professional manufacturing industry, it is necessary for the equipment manufacturing industry to establish a professional and technical team with high innovation ability if it wants to have the leading manufacturing ability and level that exceed the industry level, including high-level innovative scientific and technical talents with advanced levels and core technologies at home and abroad, academic leaders with strong leading ability, research and development backbone with scientific research and exploration spirit, etc. The introduction of a corresponding policy to encourage innovation, to bring its high-quality capabilities and due level into play, to implement the knowledge product strategy, to focus on the replacement of old drivers for new ones, and to meet the requirements of the construction of a harmonious society, will certainly have a great impact on the cultivation of world-class standards, the development of local industries, and great economic and social benefits, which is crucial for the cultivation of new 
drivers and the transformation of traditional drivers.

\subsection{Demand for High-Skilled, High-Quality Professional and Skilled Personnel}

The replacement of old drivers for new ones requires a large number of skilled talents with comprehensive knowledge structure of equipment manufacturing industry to be able to deal with and solve problems when encountering problems in the process of replacement of old drivers for new ones, not only to be competent for their own jobs, but also to continuously learn and improve their business level to meet the new requirements of the transformation process, as well as a large number of high-quality talents with the latest technical operation ability. Only in this way can production be promoted from quantitative change to qualitative change and developed to a high-end level in the process of replacement of old drivers for new ones. In order to speed up the replacement of old drivers for new ones, it is necessary to quickly cultivate a group of skilled teams with excellent quality, comprehensive technology, reasonable organization and stable quantity, taking professional quality and skills as the core, technicians and senior technicians and mechanics as the main body, carrying forward the modern "artisan spirit", so as to form a strong professional skill team capable of fighting.

2.3 Demand for Management Talents with Strong Adaptability and High Management Level

Managers should not only have high basic quality of business administration, but also know the basic professional knowledge of professional manufacturing industry. Senior managers should also be able to point out the direction for the replacement of old drivers for new ones of the equipment manufacturing industry from a global or broader perspective, and give full play to the leading role. Both senior managers and general managers need to focus on the new requirements and trends of modern management development, strengthen the cultivation of managerial talents, take improving the market competitiveness and modern management level of equipment manufacturing enterprises as the core of enterprise management, and focus on the cultivation of professional managers, so as to cultivate a group of enterprise management experts and experts who are familiar with domestic and international markets and have pioneering and innovative spirit [2].

\section{PROBLEMS IN PERSONNEL TRAINING OF EQUIPMENT MANUFACTURING INDUSTRY UNDER THE NEW REQUIREMENTS}

3.1 Fewer Professional and Technical Personnel with Strong Basic Knowledge and Strong Application Ability 
At present, China's equipment manufacturing industry has won an important position in the international market with huge market demand and low production cost, so its comparative advantage is mainly labor-intensive. In order to realize the development of equipment manufacturing industry towards low energy consumption, low pollution and high quality in our country, it is necessary to establish a stable, high-tech team to build our own core competitiveness, follow the scientific development route and achieve the goal of long-term sustainable development. At present, due to many reasons, there is serious brain drain in equipment manufacturing industry, insufficient management experience and professional skills of employees. For example, in Guangdong Province, most of the employees in the equipment manufacturing industry are migrant workers, who lack professional level and work experience, while the mature technicians are too mobile, which often makes the secrets of enterprises leak out in the process of mobility, which in the long run are bound to have extremely adverse effects on the healthy development of the equipment manufacturing industry. Therefore, a relatively stable technical talent team with strong professional development ability must be established in order to have the ability to cultivate new drivers and upgrade traditional ones in the equipment manufacturing industry.

\subsection{Low Level of Education and Professional Quality}

In China's high-end manufacturing industry, the education level of professional technicians is mainly college degree, and some enterprises have almost zero practitioners with postgraduate education level, indicating a large gap of highly educated technical personnel, and relatively low proportion of practitioners with senior professional titles. Obviously, the low cultural level and comprehensive ability of the skilled workers in China's high-end manufacturing industry have seriously restricted the development of China's equipment manufacturing industry.

\subsection{The Serious Aging of Skilled Personnel in the Manufacturing Industry}

According to the data of the Chinese Academy of Personnel Science, among technicians and senior technicians, about $40 \%$ are technicians over 46 years old, 50\% are senior technicians over 50 years old in mechanical industry, with an average age of nearly 49 years old, over $30 \%$ of technicians are over 50 years old, with an overall average age of 45.6 years old, and $57.5 \%$ of senior technicians are over 40 years old, with an average age of 41.3 years old. However, the proportion of young technicians is relatively small. Such an aging situation will definitely have two impacts on equipment manufacturing industry in China, one is the absorption and introduction of new technologies, the other is the inheritance of old technologies, which will seriously hinder the development and innovation of the high-end manufacturing industry in 
China.

\subsection{Imbalance of Skilled Talents Structure}

The development of national economy and society cannot be separated from the skills of skilled workers. According to the data from the Ministry of Social Security and the Ministry of Labor, 140 million workers are distributed in urban areas, of which about 70 million are skilled workers, including $4 \%$ of senior skilled workers, $36 \%$ of intermediate skilled workers and $60 \%$ of junior skilled workers, indicating that the structure of skilled personnel in China is seriously imbalanced and there is a large gap compared with that in developed countries. Among the 3.5 million skilled workers in urban collective enterprises and state-owned large and medium-sized enterprises in Zhejiang, where China's manufacturing industry is developed, the proportions of junior workers, intermediate workers and senior workers are $34.3 \%, 22.8 \%$ and $16.1 \%$, respectively, while the proportions in developed countries far exceed those in China: $35 \%$ are senior skilled workers and $50 \%$ are intermediate skilled workers. Thus, in China, the structure of skilled workers and the composition of knowledge and skills can no longer meet the development of high-end manufacturing technology informatization.

\subsection{Lack of Effective Training}

At present, the equipment manufacturing enterprises in China are too superficial in the training of technical talents, with insufficient investment and inadequate training mainly because, firstly, the training period of technical talents is longer than that of other industries, especially the training of advanced technical talents only depends on the education and training in technical schools or colleges, which is not enough. It also needs to create various practical opportunities to accumulate work experience in actual work, which requires enterprises to invest a large amount of manpower, material resources, financial resources and time in the development and training of technical talents. However, most enterprises only pay attention to immediate interests, neglect long-term planning, are unwilling to invest in human resources, and unilaterally pursue the short-term benefits brought by material investment. Second, there are certain risks in the development process of technical talents. At present, there is a serious shortage of technical personnel, especially senior technical personnel, in China's equipment manufacturing industry, which is bound to cause enterprises in the industry to use various means and methods to attract technical personnel from other enterprises, resulting in a white-hot competition for technical personnel, which often causes the hard-earned technical personnel trained by enterprises to be poached by other enterprises before creating value for the enterprises [3]. 


\section{THE SUPPORTING STRATEGY OF HUMAN RESOURCES TRAINING FOR THE REPLACEMENT OF OLD DRIVERS FOR NEW ONES IN EQUIPMENT MANUFACTURING INDUSTRY}

4.1 Accelerating the Gathering of High-Level Talents, and Lead the Direction of the Replacement of Old Drivers for New Ones

\subsubsection{Form the core position of high-tech talents}

High-tech talents play an important role in the transformation of old and new kinetic energy in equipment manufacturing industry, so it is necessary to cultivate and introduce the elites in the research frontier at home and abroad through various hard or soft policies based on the domestic and foreign Internet, Internet of Things, big data, artificial intelligence, 3D printing, intelligent manufacturing and other fields, such as the "Hundred Talents Program", "Thousand Talents Program", Changjiang Scholars and other high-level talents to form the core of the innovation team in equipment manufacturing industry.

\subsubsection{Playing a supporting role of high skilled talents}

First of all, higher vocational education institutions are the bases for early training and continuous improvement of technical talents, and an important way to supply skilled talents, so it is necessary to give full play to the training ability and level of higher vocational education institutions, and cultivate and export skilled talents that can support the replacement of old drivers for new ones for equipment manufacturing enterprises; secondly, in order to meet the requirements of new technologies and new skills, priority should be given to the professionals who have worked in Fortune 500 companies, are certified by the international certification system, and are outstanding in international and national skill competitions, so as to ensure the reliability requirements of technical support in the process of replacement of old drivers for new ones from above two aspects.

\subsubsection{Establishing a reserve of young technical and skilled personnel}

Young talents are the future and the new force of the enterprise, because the quality of the construction of the youth team and the level of science and technology formed are directly related to the speed and state of the future survival, development and growth of the enterprise. Therefore, the cultivation of young talents is a long-term and arduous systematic project, which requires emancipating the mind, listening carefully, constantly exploring, coordinating and cooperating, or adopting more active training methods, such as establishing a post-doctoral 
mobile station to provide powerful successors for the replacement of old drivers for new ones [4].

4.2 Improving the Overall Quality of Workers and Give Full Play to the Supporting Role of the Replacement of Old Drivers for New Ones

In order to improve the overall quality of all workers in an enterprise, it is unrealistic to rely solely on the introduction and key training, both in cost and time. Therefore, an enterprise should have sufficient enthusiasm to carry out the training of its own workers.

First, enterprises should establish the concept of training existing talents is more important than the introduction of talent [5]. The talents recruited from other enterprises often need to be retrained due to the existence of corporate differences. At the same time, the existing personnel often leave the enterprise due to the neglecting. Therefore, enterprises should keep in mind that the cultivation of existing personnel is the most cost-effective both economically and practically.

Second, attention should be paid to the construction and improvement of talent selection system within enterprises. Enterprises should implement open recruitment, formulate employee training plans and systems, and implement the training mechanism of "mentoring", so as to make employees have broad career prospects, retain enterprise talents and have sufficient opportunities to receive re-education, and ensure that the technical level of employees can keep up with the job requirements all the time, and the new employees can become talents quickly and at low cost.

Third, staff welfare and salary incentive system should be improved. In order to retain talents and stimulate their enthusiasm and enthusiasm for work, enterprises can set different wage standards according to different positions, link employees' wage income with enterprise performance, support the cost of employees' re-education, and reward them when they obtain corresponding qualifications. ${ }^{[6]}$

4.3 Paying Attention to Innovative Talents to Realize the Accurate Assistance for the Replacement of Old Drivers for New Ones

Innovation is the driving force for development and an important way to improve the level of productivity. The replacement of old drivers for new ones in the equipment manufacturing industry should also be based on unremitting innovation, whose fundamental source is to rely on the common participation of all the broad masses of workers. Therefore, great importance 
should be attached to the cultivation of the existing staff's innovative consciousness, fully mobilize their enthusiasm in innovation in production and work, tap the actual and potential talents of the staff, recognize and support various innovative achievements, actively encourage various good ideas, and form a good and long-term innovation mechanism for the enterprise.

\subsubsection{Paying attention to the establishment of talent innovation thought}

First of all, it is necessary to cultivate employees' strong sense of professionalism and corporate responsibility, because only those with a sense of responsibility and professionalism can have a strong sense of urgency, constantly break through themselves, seek new development and creatively solve the problems encountered. Secondly, attention should be paid to the grasp of comprehensive knowledge, because comprehensive knowledge is the foundation and premise of creation, which is beneficial to the association of thinking and the divergence of thinking by using the similarity and linkage of knowledge. Finally, the relative independence of thinking must be guaranteed, because the relative independent thinking is not blind and superstitious, and can find problems independently, think independently, and finally realize the innovation of thinking.

\subsubsection{Focusing on cultivating talents' innovative ability}

The favorable development point for the enterprise must encourage the employees to practice more in their work by ways of finding ways and creating conditions. In particular, the innovation of the employees of the enterprise cannot be polished off, especially for the newcomers in the enterprise, because they will bring different working abilities and methods from those of the enterprise. The management and culture of the enterprise must be conducive to this ability and method to produce innovative results in the work, so as to give play to their creativity.

\section{REFERENCES}

[1] Zhang Lan. Empirical analysis of comprehensive evaluation model of skilled talents in high-end equipment manufacturing industry. Hebei University, 2014.

[2] Han Bin. Four types of talents help the transformation of old and new kinetic energy. Dazhong Daily, 2017(10).

[3] Li Xiangqian. An empirical study on the development of skilled talents in manufacturing enterprises. Contemporary economic management, 2008, (2)84-87.

[4] Fan Wen. Speed up the training of young technical talents. Human resources development, 2009, (2) 58 . 
[5] Hu Bin, Jiang Yeqin. Research on the development countermeasures of skilled talents in equipment manufacturing industry. Journal of Ningbo Institute of Engineering. 2012, (1)86-89.

[6] Luo Ye. Application of psychological theory in salary and Welfare Design. Psychological monthly. 2019, (1), 21-23. 